\title{
GESTÃO NO CONTROLE DE ESTOQUE: ESTUDO DE CASO EM MONTADORA AUTOMOBILÍSTICA
}

\section{INVENTORY STOCK CONTROL: CASE HISTORY AT NA AUTOMOBILE MANUFACTURING}

\author{
Fabio Jun Kunigami ${ }^{1}$; Wislei Riuper Osório ${ }^{2}$ \\ ${ }^{1}$ Honda Automóveis Brasil - HAB - Sumaré, SP; Brasil, Gerente na controladoria de estoques \\ fabio jun@hbhonda.br \\ ${ }^{2}$ Faculdade Network, Campus Nova Odessa, SP, Brasil e Universidade de Campinas, UNICAMP - \\ Campinas,SP \\ wislei@,fem.unicamp.br e adm@nwk.edu.br
}

\begin{abstract}
Resumo
O objetivo deste artigo foi elaborar um sistema que contribua para o equilíbrio do estoque de bronzinas (peças utilizadas em motores) da empresa Honda Automóveis do Brasil Ltda para os modelos CIVIC e FIT, de maneira que pudesse melhorar a disponibilidade e reduzir os custos com estoque por meio de um sistema de controle de estoque e abastecimento dessas peças. Realizou-se o confronto do estoque atual por intermédio de um inventário das bronzinas em meados de setembro de 2006. Esse inventário foi comparado com os parâmetros de controle de estoque propostos. Com os novos parâmetros verificou-se uma considerável redução da quantidade dos itens estudados e dos valores em estoques parados. No caso dos estoques das bronzinas dos modelos FIT e CIVIC reduções na ordem de $R \$ 800$ mil (aproximadamente 42\%) e por volta de $R \$ 170$ mil (33\%) quando comparado com a política de reposição atualmente aplicada. Observou-se também que cuidados devem ser tomados nos cálculos dos parâmetros de estoque. Os valores de demanda e estoque de segurança podem afetar significativamente os estoques, em que determinadas peças o tempo de reposição pode ser reduzido e para outras esse tempo pode ser ampliado.
\end{abstract}

Palavras-chave: controle de estoque; estoques de segurança, reposição.

\section{Introdução}

A Revolução Industrial com certeza transformou a face do mundo, marcando o início da produção industrial moderna. Ao longo do tempo as empresas têm variado muito em como administrar o seu trabalho e em como produzir seus produtos para atender o mercado. Um dos problemas que vem acompanhando os administradores é decidir a quantidade a ser produzida. A dúvida é: produzir demais gera custos e produzir menos gera o não atendimento, desgaste na imagem da empresa e perda de clientes (MARTINS; ALT, 2003). O ponto de equilíbrio é resposta 
para essa dúvida e é o objetivo que os administradores estão sempre em busca. Um problema igualmente importante aos outros citados que também deve ser resolvido, é o controle de estoques ou administração de recursos. A importância dos estoques é fundamental para a indústria. Os estoques permitem certas economias na produção e com freqüência não consegue responder rapidamente a aumentos bruscos na demanda, havendo a necessidade de estoques desses produtos para suprir esses aumentos, em outras ocasiões a entrega da matéria-prima não é entregue conforme a necessidade da produção, justificando os estoques.

As necessidades dos clientes devem ser analisadas para que a empresa avalie se poderá atendê-las. É vital que as empresas possuam um sistema de armazenamento de materiais bem administrado para que seja possível sua rápida recuperação e para que entregas sejam facilitadas tanto para a própria empresa quanto para seus clientes. Identificou-se que as bronzinas estavam com o estoque muito alto, e outras, com estoque baixo ocasionando paradas na produção, gerando muito desperdício e alto custo para a empresa. Um sistema de controle de estoque é fundamentalmente um conjunto de regras e procedimentos que permite responder a algumas perguntas e tomar algumas decisões sobre estoques (MOREIRA, 1993).

As empresas normalmente mantêm centenas, algumas outras, milhares de materiais em estoque. A administração de todos esses materiais é um trabalho difícil. É complicado manter a mesma atenção e método de controle de um item para todos os outros. Mas há itens que devem ser controlados separadamente com uma atenção especial devido sua importância em termos do alto índice de investimento ou importância técnica do item na produção. $\mathrm{O}$ desafio do gestor de estoques é saber quando e quanto ressuprir de cada material e quanto deve manter em estoque de segurança. Com o crescente número de itens com diferentes padrões de demanda e características específicas, a complexidade na administração de materiais aumenta devido à necessidade de um controle diferenciado (SANTOS ; RODRIGUES, 2006).

O objetivo geral deste artigo foi elaborar um sistema que contribua para o equilíbrio do estoque de bronzinas (peças utilizadas nos motores HONDA) da empresa Honda Automóveis do Brasil Ltda. Para os modelos CIVIC e FIT, de maneira que pudesse melhorar a disponibilidade e reduzir os custos com estoque por meio de um sistema de controle de estoque e abastecimento dessas peças. O desafio foi manter disponível um estoque adequado de materiais que atendesse a demanda no momento certo e na hora certa de tal forma que nem faltas, nem excessos de bronzinas ocorressem, ou seja, manter o estoque equilibrado. 


\section{Gestão e parâmetros de estoques}

A administração de recursos tem sido a preocupação de gerentes, engenheiros, administradores e de todas as pessoas envolvidas direta ou indiretamente às áreas produtivas, tanto de bens quanto de serviços (MARTINS; ALT, 2003). De acordo com Moreira (2003), há dois pontos principais segundo os quais a gestão de estoques adquire grande importância e merece cuidados especiais: o operacional e o financeiro. Do ponto de vista operacional os estoques permitem certas economias na produção e também regulam as diferenças de ritmo entre os fluxos principais de uma empresa. Do ponto de vista financeiro, basta lembrar que estoque é investimento e conta como parte do capital da empresa (MARTINS; ALT, 2003; MOREIRA, 1993; SANTOS; RODRIGUES, 2006). A administração de materiais tecnicamente bem aparelhada é, sem dúvida, uma das condições fundamentais para o equilíbrio econômico e financeiro de uma empresa (FRANCISCHINI, 2002).

O conceito de controle é definido como um fluxo de informações que permite comparar o resultado real de determinada atividade com seu resultado planejado. Esse fluxo de informações pode ser visual ou oral, mas recomenda-se que seja documentado para que possa ser analisado, arquivado e recuperado quando necessário. O controle de estoque é necessário para que a empresa tenha o menor estoque possível, contanto que não falte mercadoria para ser vendida aos seus clientes (FERREIRA, 2008).

A gestão de estoques é considerada como elemento fundamental para a redução e o controle dos custos totais e melhoria do nível de serviço prestado pelas empresas (WANKE, 2003, p. 11). A gestão de estoques constitui ainda uma série de ações que permitem ao administrador verificar se os estoques estão sendo bem utilizados, bem manuseados e bem controlados (DIAS, 1997). Em meados dos anos 80 houve uma "corrida" das empresas para baixarem seus estoques a todo custo, sem preocupação com os possíveis impactos correlacionados (CORREA et al, 2001).

Reporta-se em literatura (MARTINS; ALT, 2003; DIAS, 1997) dois aspectos importantes, isto é, o conhecimento da demanda e a obtenção dos materiais, podem influenciar decisivamente o estoque. Em literatura (KLASSEN; MENOR, 2007; SANDRINI; MESQUITA, 2008) também se reporta que maiores níveis de capacidade de produção exigem menores níveis de estoque, e viceversa, o que caracteriza um trade-off. Iniciativas que visem a redução das variações, como estabilidade do processo, redução dos tempos de setup e quebras de equipamento, faz o sistema operar com menores níveis de capacidade e/ou estoque para garantir um bom nível de serviço (SANDRINI; MESQUITA, 2008). Sandrini e Mesquita (2008) em estudos experimentais verificaram que o aumento da variação de demanda exige um maior estoque de segurança para acomodação ou minimização das incertezas. Verificou-se que o nível de serviço de 99,9\% não foi 
conseguido nos casos em que o nível de utilização planejado é de $100 \%$, ainda que o nível de estoque seja muito alto.

Lenard e Roy (1995) afirmam que o controle de estoque é estudado desde 1913 com Harris ao introduzir a fórmula do lote econômico de compra. A adoção de certas regras define a forma de aquisição de materiais, procurando responder às questões de quando comprar e quanto comprar (TUBINO, 2004). Para tanto, a empresa deve definir e implantar alguns parâmetros de ressuprimento de estoques como: Estoque máximo ( $\left.E_{\text {máx. }}\right)$ e Estoque de segurança $\left(E_{S}\right)$ que definem a quantidade de abastecimento, calculada com o estoque real acrescido das quantidades de encomendas aos fornecedores e a quantidade mínima possível capaz de suportar o tempo necessário para reabastecimento (TUBINO, 2004). O estoque de segurança $\left(E_{S}\right)$ pode representar o estoque de produtos para suprir determinado período, além do prazo de entrega para consumo ou vendas, prevenindo possíveis atrasos na entrega por parte do fornecedor (TUBINO, 2004). Sabe-se que devido à dificuldade de se balancear com precisão o custo da falta e o custo do excesso, o estoque de segurança deve ser calculado com base no conceito de nível de serviço, que se refere à probabilidade de que a falta de um produto em estoque não ocorra (GAITHER; FRAZIER, 2004; TUBINO, 2004, CASTRO; PIZZOLATO, 2005; GARCIA et al, 2008; SILVA et al, 2008). A importância do Estoque de Segurança é a chave para o adequado estabelecimento do ponto de pedido. Os valores de $\mathrm{E}_{\mathrm{S}}$ podem calculados a partir da Equação 1.

$$
E_{S}=f_{S} \times \sigma
$$

onde:

$\mathrm{f}_{\mathrm{s}}=$ fator de segurança (definido como função do nível de serviço desejado (TUBINO, 2004)); e

$\sigma=$ desvio padrão das demandas avaliadas.

Quanto maior o tempo de reposição entre fornecedor e empresa ou mais problemático for o fornecedor em relação ao prazo de entrega, os estoques de segurança deverão ser maiores. A determinação do risco que queremos correr, ou em outras palavras do nível de serviço do item, é função de quantas faltas admitimos durante o período de planejamento como suportável para este item. Determinar quanto fazer um novo pedido de compra para reposição do item em estoque é um dos grandes problemas do Administrador de Materiais. A quantidade em estoque que, quando atinja, deve acionar um processo de compra ou fabricação, chamado ponto de pedido (FRANCISCHINI, 2002). Para a definição do ponto de pedido (PP) ou ressuprimento, o estoque de segurança deve ser somado com a demanda durante o lead time, independente da fórmula de cálculo 
(TUBINO, 2004; CHAN et al, 1999; BALLOU, 2001; KREVER et al, 2003; ZOMERDIJK; VRIES, 2003; PARTOVI; ANANDARAJAN, 2002; PEREIRA, 2008; GARCIA et al, 2008) como se segue:

$$
P P=\left(d_{t} \times t_{r}\right)+E_{S}
$$

onde:

$\mathrm{d}_{\mathrm{t}}=$ demanda diária; $\mathrm{e}$

$\mathrm{t}_{\mathrm{r}}=$ tempo de reposição ou ressuprimento.

Para calcular o momento em que devemos fazer o pedido de compra, todas essas simplificações estão presentes e, de alguma maneira devem ser absorvidas pelo estoque de segurança. Como o próprio nome indica, o sistema do Lote Econômico de Compra foi concebido para a gestão de itens comprados fora da empresa. É possível, no entanto, com algumas adaptações simples, aplicá-lo ao caso de itens internamente fabricados. No caso do Lote Econômico de Compra é utilizada apenas a sigla LEC (MOREIRA, 1993), que pode também ser representado pela quantidade de pedido de ressuprimento que minimiza a soma do custo de manutenção de estoque e emissão e colocação de pedido (BOWERSOX E CLOSS, 2001, p.236).

Com relação ao "quanto comprar", Tubino (2004) relata que para adoção do ponto de pedido é importante que se defina também a quantidade a ser pedida, determinando o tamanho do lote, por meio do lote econômico de compras (LEC ou Q*), definido pela Equação 3. Quanto mais vezes se comprar ou se preparar a fabricação, menores serão os estoques médios e maiores serão os custos decorrentes do processo tanto de compras como de preparação. Assim, os custos de compras e preparação são inversamente proporcionais aos estoques médios (MARTINS; ALT, 2003). Para adoção do PP é importante que a quantidade de compra seja definada, por meio do lote econômico de compras (LEC ou $\mathrm{Q}^{*}$ ), como se segue:

$$
Q^{*}=\sqrt{\frac{2 D}{C} \cdot k}
$$

onde:

$\mathrm{D}=$ demanda no período;

$\mathrm{C}=$ custo unitário do medicamento no período;

$k=$ fator de poder de compra (PEREIRA, 2008; GARCIA et al, 2008; GARCIA; OSÓRIO, 2008). 
Críticas referentes aos modelos clássicos de estoque são comumente encontradas em literatura (FERREIRA, 2008; BALLOU, 2001; TUBINO, 2004) devido às limitações encontradas no confronto do modelo com o mundo real ou na determinação dos custos de pedido, de manutenção e encargos sobre o produto (ZOMERDIJK; VRIES, 2003; MOREIRA, 1993; PEREIRA, 2008). Para isso aproximações podem ser feitas para minimizar esses efeitos.

\section{Metodologia}

Sabe-se que o controle e gerenciamento de estoques multi-itens é bastante complexo devido à diversidade (PARTOVI; ANANDARAJAN, 2002). Especula-se ainda que se uma rede de portais de relacionamento com fornecedores for firmada entre as indústrias automobilísticas, benefícios como a redução do custo de transação e a informação online podem ser conseguidos (TURBAN et al, 2004; RODRIGUES; SELLITTO, 2008). Os itens escolhidos como foco neste estudo foram as bronzinas que são formadas por duas partes iguais de aço revestido com metal anti-fricção, conforme mostrado nas Figuras 1 e 2. As bronzinas apresentam um sulco que permite a passagem de óleo, elas são divididas em três tipos:

a) Bronzina Connrod: Bronzinas montadas na cabeça das Bielas ligadas com o Virabrequim. Existem seis espessuras diferentes para o modelo Civic e sete para o modelo Fit. Há também Bronzinas Connrod exclusivamente para a montagem dos motores CIVIC gasolina com seis espessuras diferentes;

b) Bronzina Main Upper: Bronzinas montadas no encaixes superiores do Bloco do Motor com o Virabrequim. Existem seis espessuras diferentes para o modelo Civic e oito para o modelo Fit;

c) Bronzina Main Lower: Bronzinas montadas no encaixes inferiores do Bloco do Motor com o Virabrequim. Existem seis espessuras diferentes para o modelo Civic e oito para o modelo Fit. 
Figura 1: Esquema de montagem das Bronzinas Connrod
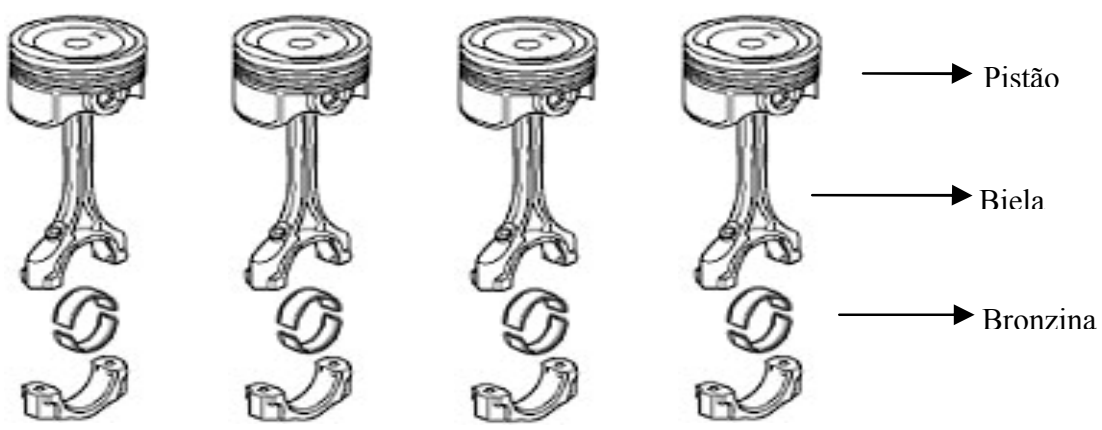

Fonte: Honda Automóveis do Brasil Ltda (2008).

Para a montagem dos motores, os blocos são produzidos no Japão e no Brasil. Durante a produção desses blocos pela origem (JPN ou BR) a máquina que as produz faz as medições de cada mancal e estampa em forma de letras no próprio bloco. A fabricação das bielas e virabrequins são todos de origem JPN, produzidas com procedimentos diferentes, porém com as medições e identificações das medições parecidas, que é o objeto de interesse neste estudo.

Figura 2: Esquema de montagem das Bronzinas Main Upper e Main Lower

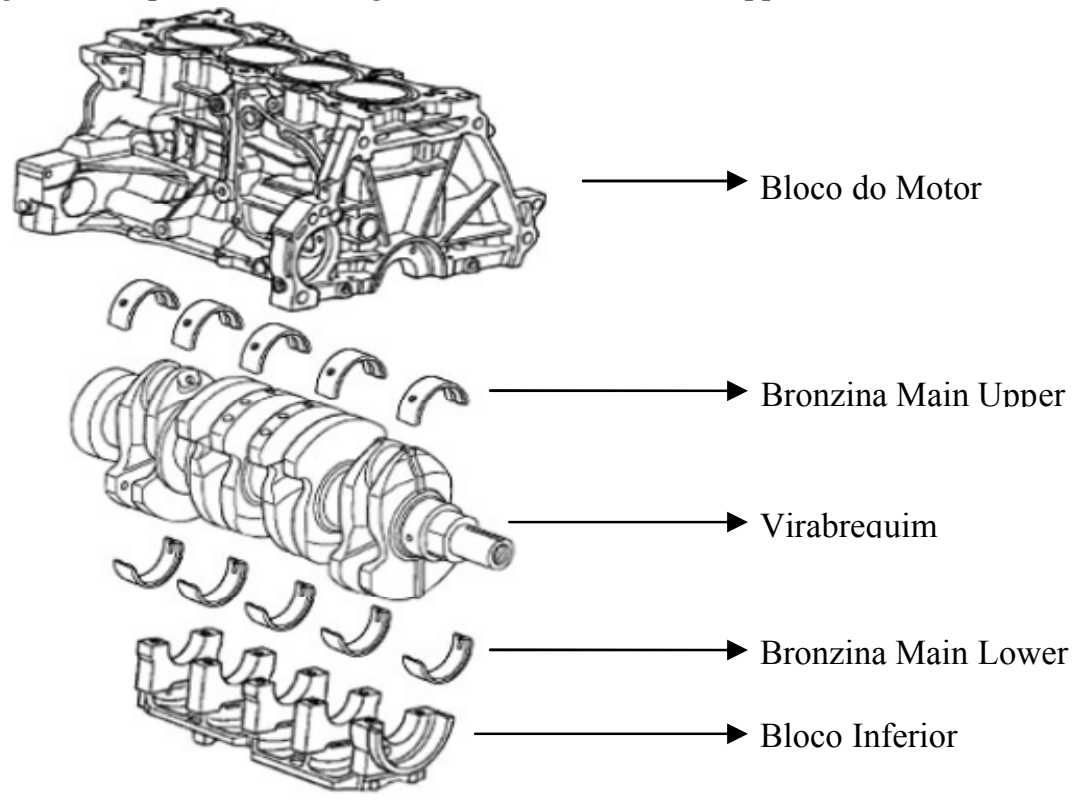

Fonte: Honda Automóveis do Brasil Ltda (2008).

Nos virabrequins são estampados quatro números para a identificação das medições dos mancais onde são montadas as bielas e cinco letras para os mancais onde se encaixa no bloco do motor. Na fabricação das bielas há estampado um número de 1 a 4 variando com a medição de cada Biela, conforme mostra Figura 3. 
Figura 3 Esquema de numeração no bloco do motor e virabrequim

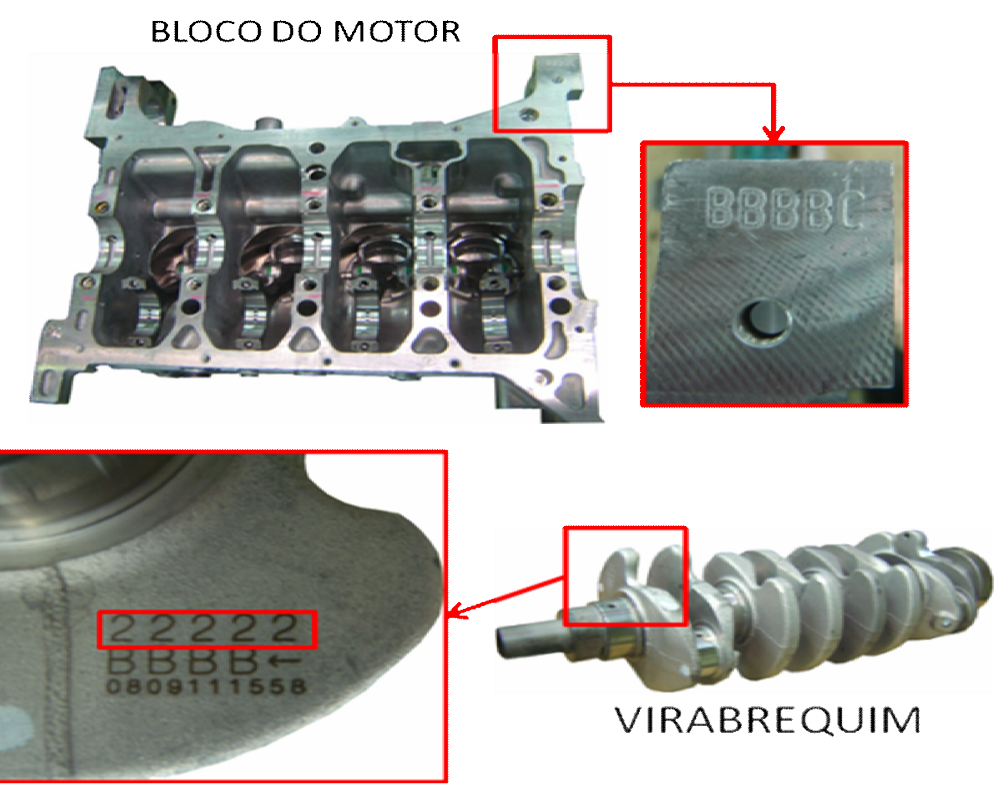

Fonte: Honda Automóveis do Brasil Ltda (2008).

A seleção das bronzinas do tipo main upper e lower e connrod para os modelos FIT e CIVIC para a montagem com bloco/virabrequim/biela é realizada com codificação de cores sendo: VM (vermelho), R (Rosa), AM (amarelo), VD (verde), MR (marrom), PR(preto) e AZ (azul), conforme mostrado na Figura 4.

Figura 4 - Esquema de seleção das bronzinas para FIT (a) e CIVIC (b)

\begin{tabular}{|c|c|c|c|c|c|c|c|c|}
\hline BLOOO VIRAB. & \multicolumn{2}{|c|}{ A } & \multicolumn{2}{|c|}{ B } & \multicolumn{3}{c|}{ C } & \multicolumn{3}{c|}{ D } \\
\hline $\mathbf{1}$ & VM & VM & R & R & AM & AM & VD & VD \\
\hline $\mathbf{2}$ & R & R & AM & AM & VD & VD & MR & MR \\
\hline $\mathbf{3}$ & AM & AM & VD & VD & MR & MR & PR & PR \\
\hline $\mathbf{4}$ & VD & VD & MR & MR & PR & PR & AZ & AZ \\
\hline
\end{tabular}

(a)

\begin{tabular}{|c|c|c|c|c|c|c|c|c|}
\hline BIEA VIRAB. & \multicolumn{2}{|c|}{ A } & \multicolumn{2}{c|}{ B } & \multicolumn{2}{c|}{ C } & \multicolumn{2}{c|}{ D } \\
\hline $\mathbf{1}$ & BR & BR & VM & VM & R & R & AM & AM \\
\hline $\mathbf{2}$ & VM & VM & R & R & AM & AM & VD & VD \\
\hline $\mathbf{3}$ & R & R & AM & AM & VD & VD & MR & MR \\
\hline $\mathbf{4}$ & AM & AM & VD & VD & MR & MR & PR & PR \\
\hline
\end{tabular}

\begin{tabular}{|c|c|c|c|c|c|c|c|c|c|}
\hline BLOC & \multicolumn{2}{|c|}{ 1, A ou I } & \multicolumn{2}{|c|}{ 2, B ou II } & \multicolumn{3}{|c|}{ 3, Cou III } & \multicolumn{2}{l|}{ 4, D ou IIII } \\
\hline $\mathbf{1}$ & RIRAB. & R & R & AM & AM & AM & AM & VD \\
\hline $\mathbf{2}$ & R & AM & AM & AM & AM & VD & VD & VD \\
\hline $\mathbf{3}$ & AM & VD & VD & VD & VD & MR & MR & MR \\
\hline $\mathbf{4}$ & VD & VD & VD & MR & MR & MR & MR & PR \\
\hline $\mathbf{5}$ & VD & MR & MR & MR & MR & PR & PR & PR \\
\hline $\mathbf{6}$ & MR & PR & PR & PR & PR & AZ & AZ & AZ \\
\hline
\end{tabular}

(b)

\begin{tabular}{|c|c|c|c|c|c|c|c|c|}
\hline VIRAB. & \multicolumn{2}{|c|}{ 1 ou I } & \multicolumn{2}{|c|}{2 ou II } & \multicolumn{2}{|c|}{3 ou III } & \multicolumn{2}{|c|}{ 4 ou IIII } \\
\hline A & VM & VM & VM & R & R & R & R & AM \\
\hline B & R & R & R & AM & AM & AM & AM & VD \\
\hline C & AM & AM & AM & VD & VD & VD & VD & MR \\
\hline D & VD & VD & VD & MR & MR & MR & MR & PR \\
\hline
\end{tabular}

Fonte: Autoria própria (2008). 
Para que os objetivos deste estudo fossem alcançados, realizou-se o confronto do estoque atual por intermédio de um inventário das bronzinas em meados de setembro de 2006. Esse inventário foi comparado com os parâmetros de controle de estoque propostos. Para isso, foram realizadas as seguintes atividades:

- Criação de um sistema de baixa automática de bronzinas utilizadas na produção;

- Levantamento da demanda de bronzinas para a produção;

- Criação de um sistema de controle de estoque, determinando os parâmetros de controle de estoque, sendo Estoque de Segurança $\left(\mathrm{E}_{\mathrm{S}}\right)$, Nível máximo de estocagem ( $\mathrm{E}_{\mathrm{máx}}$.), Ponto de pedido (PP) e Lote econômico de compra (LEC ou Q*);

- Ajuste dos pedidos com o Tempo de Reposição do fornecedor (Japão e Tailândia) e a demanda;

-Criação de um sistema de abastecimento de peças na produção;

-Análise de criticidade para determinação do estoque de segurança como função das demandas reais solicitadas na produção.

Todas as peças dos modelos CIVIC e FIT chegavam em lotes para a fabricação de 60 carros, porém, as bronzinas chegavam três peças diferentes em quantidade maior de várias espessuras. De todas as bronzinas que chegavam para a produção, eram utilizadas apenas oito nas bielas com o virabrequim e dez no bloco do motor com o virabrequim.

As bronzinas do CIVIC são de origem Japão e do FIT são de origem Tailândia. Os pedidos ou as solicitações de reposição da bronzinas são feitos para Japão e Tailândia em períodos de 30 dias, com isso existe reposição a cada 30 dias. Somente em casos de urgência de reposição, devido alterações inesperadas no consumo mensal, as reposições são feitas utilizando de modal de transporte aéreo, caso contrário, em situação normal, as reposições são feitas via modal marítimo. Por esse último modal, as entregas do Japão demoram 150 dias para reposição e de 180 para reposição oriunda da Tailândia.

Devido a todos os itens serem considerados de "alta" importância na produção, pois, sua falta ou atraso na entrada na linha de produção provoca "paradas" indesejáveis. Com isso, os itens estudados foram considerados de importância 3, ou seja, fator de segurança ( $\mathrm{Fs}=3$ ).

$\mathrm{Na}$ literatura reporta-se que um nível de serviço em torno de 99,99\% é atrelado a esse fator de segurança (BALLOU, 2001; TUBINO, 2004; SILVA et al, 2008). Isso significa que a "chance" ou a "hipótese" em se ter "faltas" no estoque é menor que 0,01\% (BALLOU, 2001; TUBINO, 2004). Essa criticidade está também "atrelada" às demandas reais solicitadas na produção. 


\section{Resultados e Discussões}

Com o propósito em se adequar a política de estoque utilizada pela empresa Honda Automóveis do Brasil Ltda. para evitar o excesso, serão realizadas comparações da política de estoques que eram utilizadas e a proposta implantada. Para um melhor entendimento, foi elaborado um gráfico onde se descrevem os valores que eram praticados e apresentam os valores correspondentes ao Estoque de Segurança $\left(E_{S}\right)$.

Nas Figuras de 5 a 8 apresentam-se as diferenças entre dos estoques dos modelos CIVIC e FIT e estoques de segurança anteriormente praticados e os estoques propostos aplicados.

Figura 5 - Comparação entre os estoques antigo e atual do modelo CIVIC entre os tipos Bronzinas, conforme codificacão de cores (Fig.4).

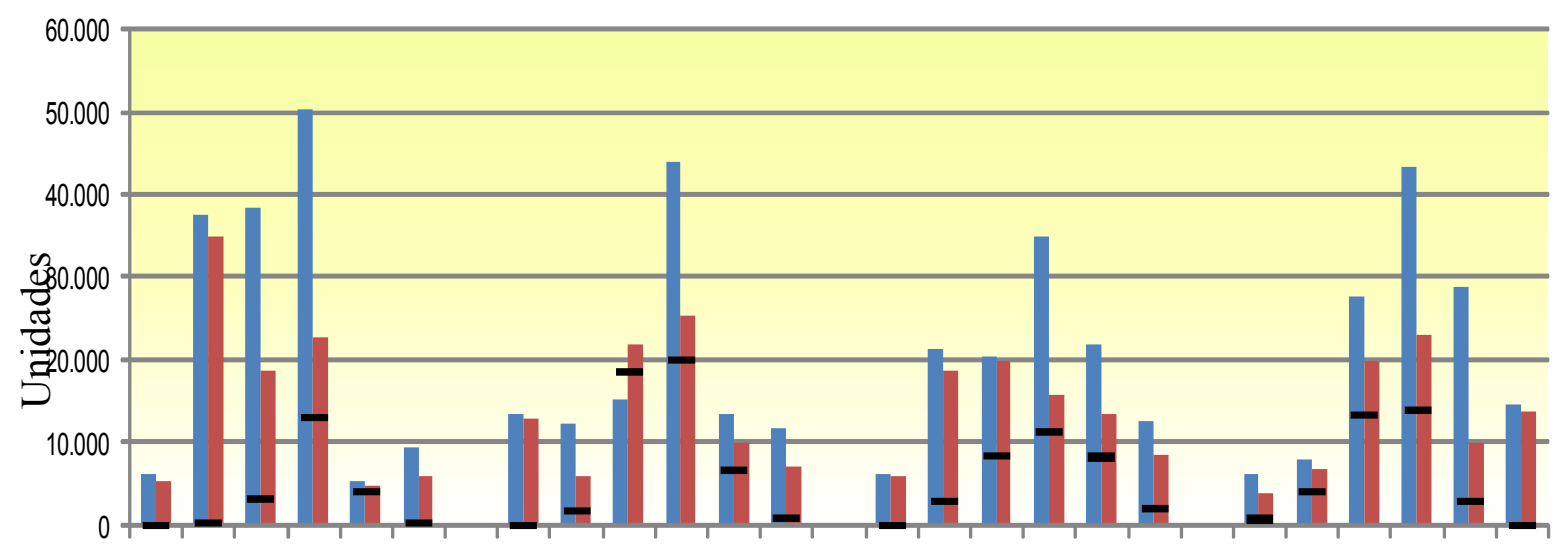

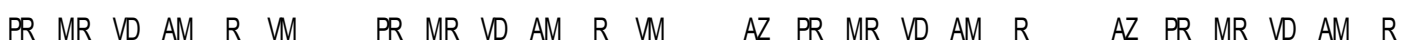

-EANTIGO IEATUAL -ES

Fonte: Autoria própria (2008).

Figura 6 - Diferença de estoque antigo e atual de Bronzinas para modelo CIVIC

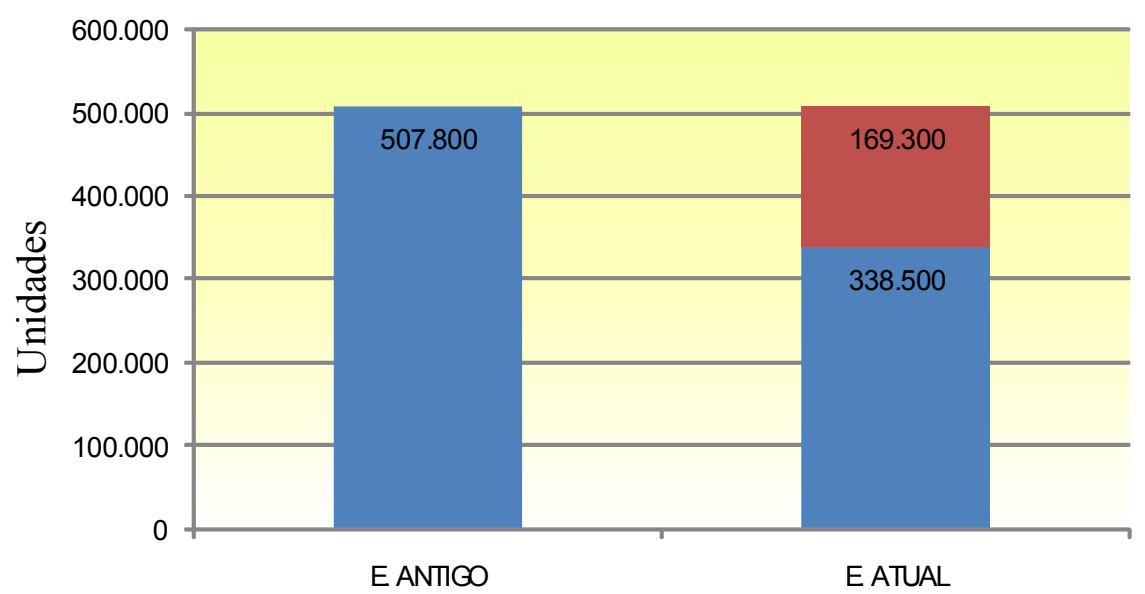

Fonte: Autoria própria (2008).

Na Figura 6 observa-se que há uma redução do estoque de Bronzinas do modelo CIVIC de quase 170 mil peças em quase dois anos, visto que, a demanda anual atual é de aproximadamente 
um milhão de peças e os estudos foram iniados no segundo sementres de 2006. Na Figura 7 apresentam-se também as comparações entre os estoques antigos e atuais do modelo FIT entre os tipos (medidas) de Bronzinas, conforme codificação de cores apresentada na Fig.4.

Na Figura 8 observa-se que a redução é de um pouco mais de 800 mil peças também em dois anos para o modelo FIT com uma demanda atual também de aproximadamente um milhão de peças. Comparando os valores mostrados, pode até se considerado que a diferença é muito pouca. Porém, a demanda é muito baixa daquelas peças (bronzinas) que estão com o "volume" maior, ocasionando um tempo alto até que esses estoques entrem em equilíbrio.

Figura 7 - Comparação entre os estoques antigo e atual do modelo FIT entre os tipos Bronzinas, conforme codificação de cores (Fig.4).

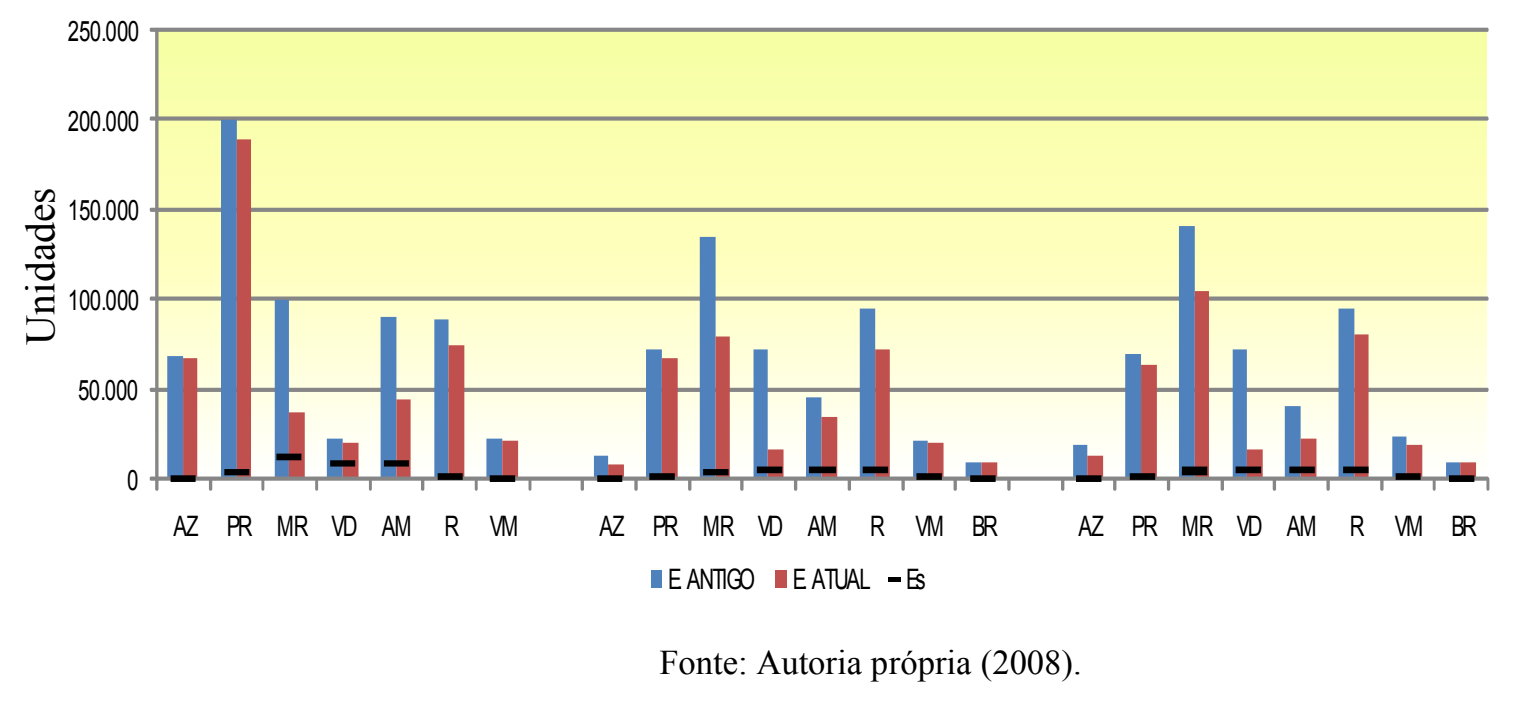

Figura 8- Diferença de estoque antigo e atual de Bronzinas para modelo FIT

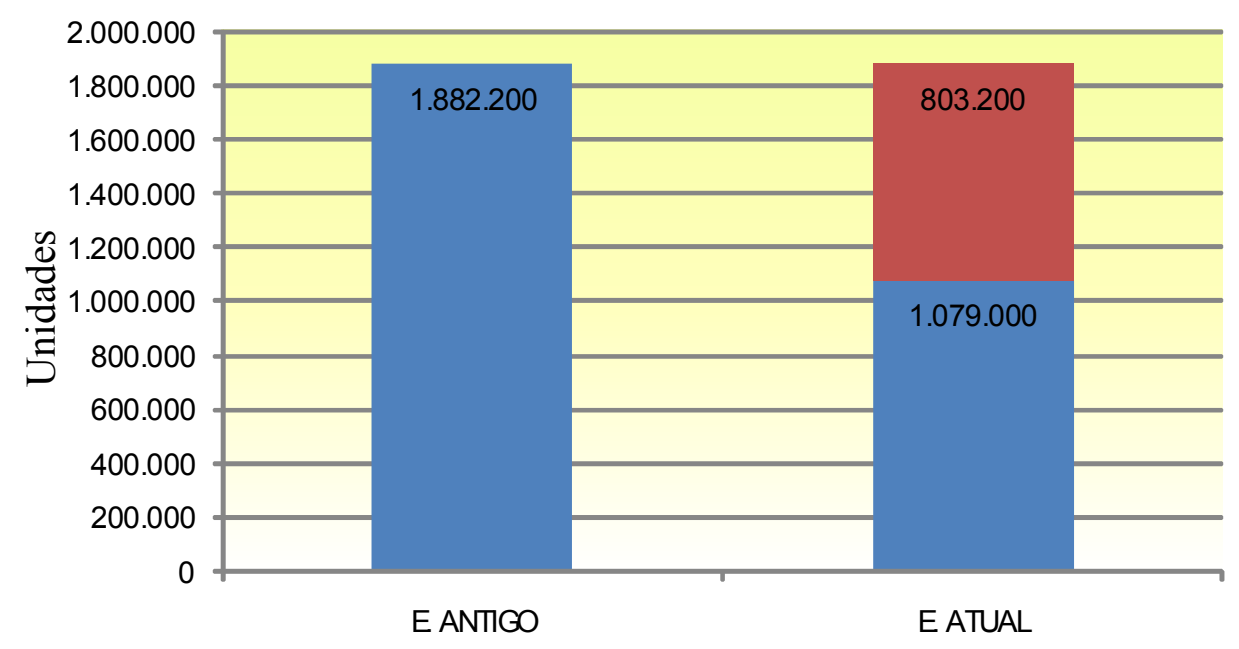

Fonte: Autoria própria (2008). 
Pelo fato das peças pesquisadas apresentarem diferentes demandas, diferentes quantidades em estoques são observadas. Na Figura 5, os itens MR, VD e AM são aqueles de maiores quantidades em estoque devido seu alto giro. Na Figura 7, também nos mesmos itens (MR, VD e $\mathrm{AM})$, estes são com menor quantidade mesmo sendo de alto giro, isto devido ao estoque das demais peças estarem com o estoque muito alto. Na redução atual dos estoques, somando-se todos os 47 itens, têm-se os valores aproximados: considerando um valor médio de $\mathrm{R} \$ 1,00$ pode-se apresentar uma valor total de R\$972 mil aproximadamente. Nas Figuras 9 e 10 apresentam-se os estoques atuais e os estoques de segurança propostos neste estudo das bronzinas dos dois modelos dos automóveis fabricados. A Figura 11 que possibilita uma melhor visão da demanda diária, estoque de segurança e da política de estoque aplicada. Essa sistemática pode ser representada para as demais peças, diferenciando uma das outras apenas pela quantidade em estoque e estoque de segurança.

Figura 9 - Comparação dos estoques atuais e estoques de segurança poprostos para modelo CIVIC

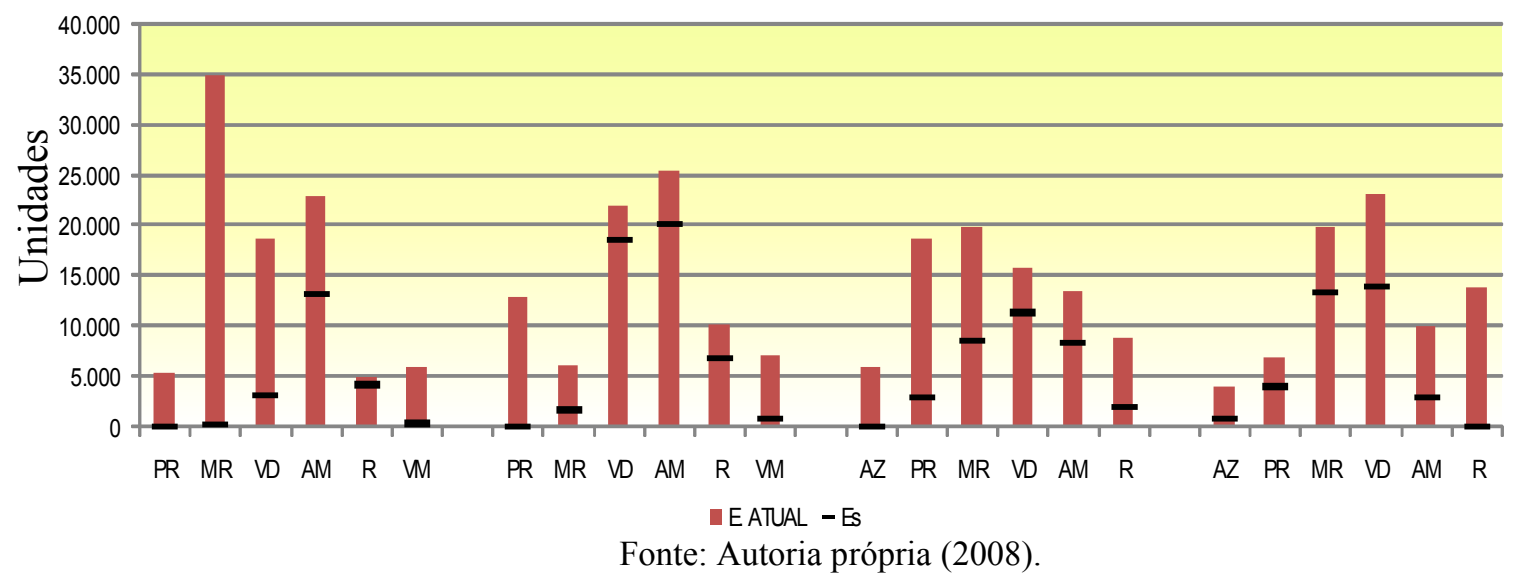

Figura 10 - Comparação dos estoques atuais e estoques de segurança poprostos para modelo FIT

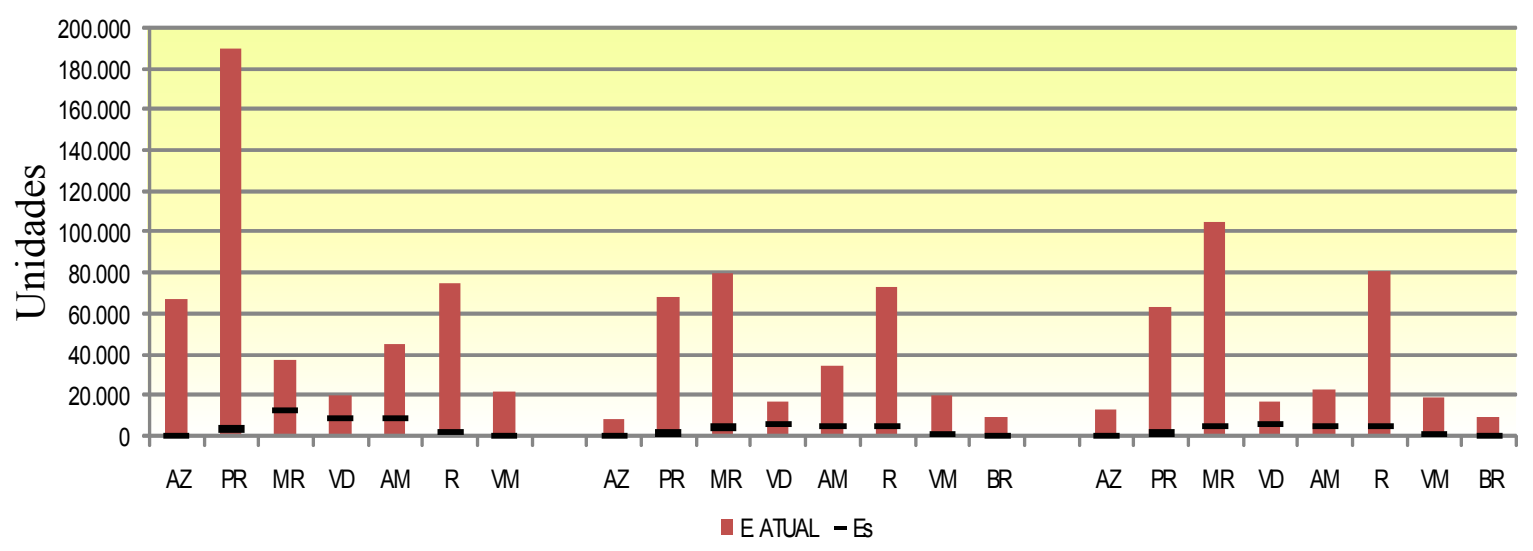

Fonte: Autoria própria (2008).

Percebe-se que nas Figuras 9 e 10, os estoques atuais e os estoques de segurança, estão mais equilibrados quando comparados com a política de reposição que era utilizada, lembrando que anteriormente a quantidade produzida de carros era menor. A forma de abastecimento do estoque 
era de forma incorreta, ocasionando um "volume" alto no estoque ou podendo ser insuficientes conforme o aumento de demanda de cada peça, e também, devido não haver estoque de segurança implantada.

Quando ocorre um estoque em excesso pode haver vários fatores críticos como desperdício e capital parado, podendo este ser destinado a outros projetos, por outro lado a falta de uma dessas peças no estoque pode afetar ainda mais o capital da empresa, como uma parada de produção que gera perdas imensuráveis.

Todas as Bronzinas são peças consideradas de classe "A" devido à demanda, independente dela alta ou baixa, a falta ou o atraso de uma dessas peças ocasiona uma "parada" na produção. Os valores dos estoques de segurança propostos foram calculados conforme a Equação 1. Nessa equação foi tomado como base o valor de fator 3 de segurança (fator de alto nível de importância) conforme a Análise de Criticidade que os itens se enquadravam. Todos os valores estudados foram determinados a partir de demandas de 12 períodos (mensal).

Na Figura 11 tem-se o Ponto de Pedido (PP, linha azul) da bronzina Connrod amarela que é de aproximadamente 44 mil peças, calculado utilizando-se da Equação 2, podendo ser considerado o mesmo tipo de cálculo para as demais Bronzinas, alterando apenas os valores, devido às diferentes demandas de cada peça. Na mesma figura tem-se também a representação (linha vermelha) do estoque de segurança $\left(\mathrm{E}_{\mathrm{S}}\right)$.

Figura 11 - Gráfico de demanda diária da Bronzina Connrod Amarela

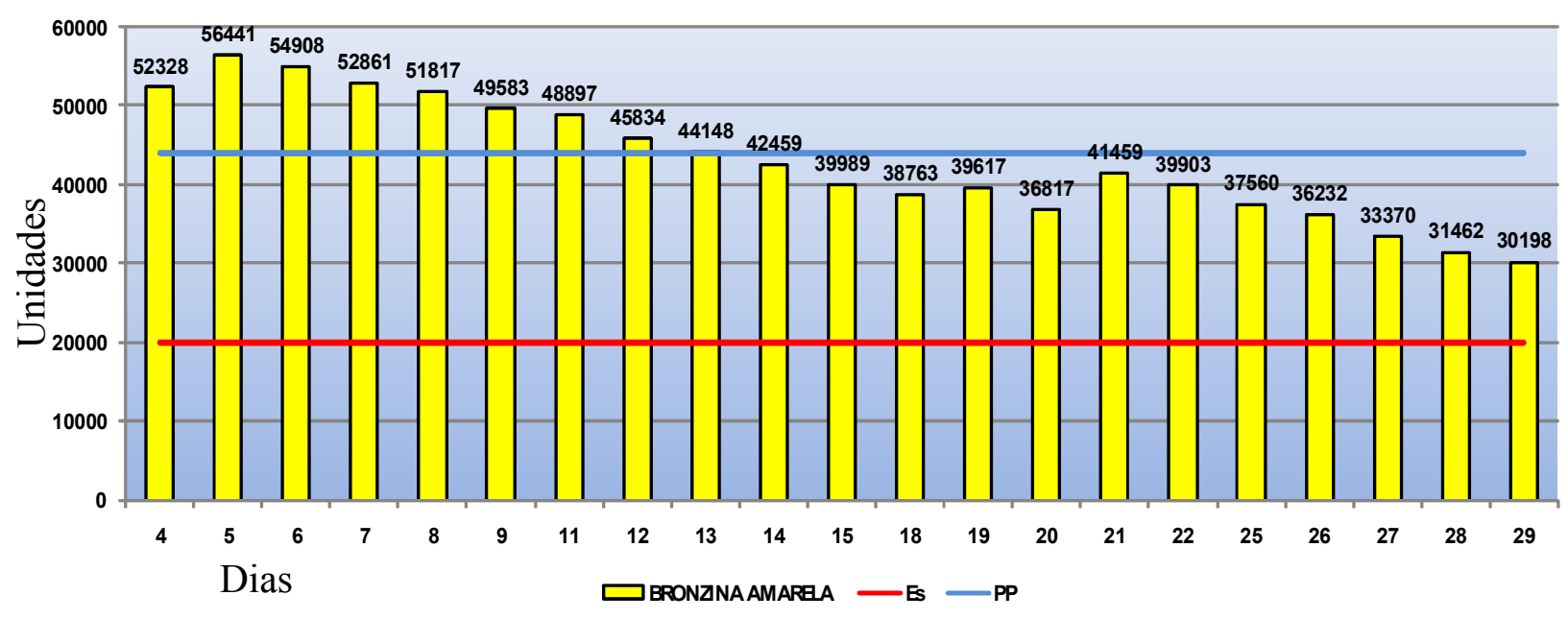

Fonte: Autoria própria (2008).

O sistema de Lote Econômico de Compra (L.E.C) não pode ser aplicado para as Bronzinas de alta demanda, isso porque quando elaborado os cálculos, o estoque máximo ( $\mathrm{E}_{\text {máx. }}$ ) fícou menor que o ponto de pedido conforme Tabelas 1 e 2. Esse fato ocorreu devido o tempo de reposição solicitado pela origem (JPN ou THAI) é muito maior que se pede para que o sistema L.E.C seja 
atendido. O fornecedor do Japão solicita um tempo de reposição maior que 150 dias e a Tailândia um tempo maior que 180 dias. Devido ao tempo de reposição solicitado pelas origens serem muito altos, os pedidos são elaborados a cada 30 dias para que os estoques fiquem em maior equilíbrio. As indicações "OK" ao lado das tabelas mostram que os tempos de reposição de 30dias são suficientes para atender às demandas de cada tipo de bronzina. Por outro lado, as indicações "estorou", mostram que os tempos de reposições devem ser menores que 30 dias. Como exemplo, na Tabela 1 os itens 12213RNA, 13214RNA e 13215RNA, deveriam ter reposições em 10, 06 e 14 dias, onde então os valores de PP, $\mathrm{E}_{\text {máx }}$ seriam alterados segundo cálculos da filosofia LEC.

Tabela 1- Parâmetros de estoque propostos para o modelo CIVIC.

\begin{tabular}{|c|c|c|c|c|c|c|c|}
\hline CÓDIGO & DESCRÇÃO & COR & $\mathbf{E}_{\text {mín. }}$ & $\mathbf{E}_{\text {máx. }}$ & PP & $Q^{*}$ & \\
\hline 13211RNA A010 M1 & BRG A , CONNROD & PRETO & 24 & 83 & 26 & 59 & OK \\
\hline 13212RNA A010 M1 & BRG B , CONNROD & MARROM & 251 & 574 & 338 & 323 & OK \\
\hline 13213RNAA010M1 & BRG C , CONNROD & VERDE & 3121 & 4419 & 4524 & 1298 & estor \\
\hline 13214RNAA010 M1 & BRG D , CONNROD & AMAREIO & 13151 & 15527 & 17857 & 2377 & estorou \\
\hline 13215RNAA010M1 & BRG E , CONNROD & ROSA & 4166 & 5435 & 5508 & 1269 & estorou \\
\hline 13216RNAA010 M1 & CONNROD & VERMELHO & 285 & 630 & 384 & 345 & OK \\
\hline
\end{tabular}

\begin{tabular}{|c|c|c|c|c|c|c|}
\hline CÓDIGO & DESCRACÃO & COR & $\mathbf{E}_{\text {mín. }}$ & $\mathbf{E}_{\text {máx. }}$ & PP & $\mathbf{Q}^{*}$ \\
\hline 13211RNE A010 M2 & BRG A, CONNROD & PRETO & 46 & 172 & 60 & 125 \\
\hline 13212RNE A010 M2 & BRG B , CONNROD & MARROM & 1669 & 2597 & 2386 & 928 \\
\hline 13213RNEA010 M2 & BRG C , CONNROD & VERDE & 18656 & 22175 & 28972 & 3518 \\
\hline 13214RNEA010 M2 & BRG D , CONNROD & AMAREIO & 20180 & 25537 & 44088 & 5356 \\
\hline 13215RNEA010 M2 & BRG E , CONNROD & ROSA & 6755 & 9273 & 12040 & 2519 \\
\hline 13216RNEA010 M2 & BRG F , CONNROD & VERMELHO & 786 & 1432 & 1133 & 646 \\
\hline
\end{tabular}

\begin{tabular}{|c|c|c|c|c|c|c|}
\hline CÓDIGO & DESCRÇÃO & COR & $\mathbf{E}_{\text {mín. }}$ & $\mathbf{E}_{\text {máx. }}$ & $\mathbf{P P}$ & $\mathbf{Q}^{*}$ \\
\hline 13321RNA A010 M1 & BRG A, MAIN UPR & AZUL & 73 & 186 & 83 & 113 \\
\hline 13322RNA A010 M1 & BRG B , MAIN UPR & PRETO & 2856 & 3602 & 3320 & 746 \\
\hline 13323RNAA010M1 & BRG C, MAIN UPR & MARROM & 8483 & 11784 & 17566 & 3301 \\
\hline 13324RNAA010 M1 & BRG D, MAIN UPR & VERDE & 11377 & 15732 & 27182 & 4355 \\
\hline 13325RNAA010M1 & BRG E, MAIN UPR & AMAREIO & 8363 & 10714 & 12971 & 2352 \\
\hline 13326RNAA010M1 & BRG F, MAIN UPR & ROSA & 1966 & 2563 & 2263 & 596 \\
\hline
\end{tabular}

\begin{tabular}{|c|c|c|c|c|c|c|c|}
\hline CÓDIGO & DESCRÇÃO & COR & $\mathbf{E}_{\mathbf{m i ́ n} .}$ & $\mathbf{E}_{\text {máx. }}$ & PP & $Q^{*}$ & \\
\hline 13341RNA A010 M1 & BRG A, MAIN LWR & $\overline{A Z U L}$ & 754 & 1138 & 877 & 384 & OK \\
\hline 13342RNA A010 M1 & BRG B , MAIN LWR & PRETO & 3999 & 5567 & 6049 & 1569 & \\
\hline 13343RNAA010 M1 & BRG C, MAIN LWR & MARROM & 13468 & 18227 & 32346 & 4760 & storc \\
\hline 13344RNAA010 M1 & BRG D , MAIN LWR & VERDE & 14002 & 17052 & 21753 & 3050 & estorou \\
\hline 13345RNAA010M1 & BRG E , MAIN LWR & AMARELO & 2976 & 4295 & 4425 & 1319 & estorou \\
\hline 13346RNAA010M1 & BRG F , MAIN LWR & $\overline{R O S A}$ & 80 & 208 & 93 & 128 & OK \\
\hline
\end{tabular}

Fonte: Autoria própria (2008). 
Tabela 2 - Parâmetros de estoque propostos para o modelo FIT.

\begin{tabular}{|c|c|c|c|c|c|c|}
\hline CÓDIGO & DESCRÇÃO & COR & $\mathbf{E}_{\text {mín. }}$ & $\mathbf{E}_{\text {máx. }}$ & $\mathbf{P P}$ & $Q^{*}$ \\
\hline 13211REA Z010 M5 & BRG A, CONNROD & $\overline{A Z U L}$ & 299 & 675 & 417 & 376 \\
\hline 13212REA Z010 M5 & BRG B, CONNROD & PRETO & 3367 & 5161 & 6050 & 1795 \\
\hline 13213REAZ010 M5 & BRG C, CONNROD & MARROM & 12701 & 16699 & 26017 & 3997 \\
\hline 13214REA Z010 M5 & BRG D, CONNROD & VERDE & 8729 & 12947 & 23554 & 4218 \\
\hline 13215REA Z010 M5 & BRG E, CONNROD & AMAREO & 8972 & 11419 & 13961 & 2447 \\
\hline 13216REA Z010 M5 & BRG F, CONNROD & ROSA & 1584 & 2403 & 2143 & 819 \\
\hline 13217REA Z010 M5 & BRG G, CONNROD & VERMELHO & 96 & 250 & 116 & 154 \\
\hline
\end{tabular}

\begin{tabular}{|c|c|c|c|c|c|c|}
\hline CÓDIGO & DESCRIÇÃO & COR & $\mathbf{E}_{\text {mín. }}$ & $\mathbf{E}_{\text {máx. }}$ & $\mathbf{P P}$ & $Q^{*}$ \\
\hline 13321REA Z010 M5 & BRG A, MAIN UPR & $\overline{A Z U L}$ & 69 & 213 & 87 & 144 \\
\hline 13322REA Z010 M5 & BRG B, MAIN UPR & PRETO & 1425 & 2160 & 1876 & 736 \\
\hline 13323REAZ010 M5 & BRG C, MAIN UPR & MARROM & 4370 & 6091 & 6840 & 1722 \\
\hline 13324REAZ010 M5 & BRG D, MAIN UPR & VERDE & 5658 & 8475 & 12273 & 2818 \\
\hline 13325REA Z010 M5 & BRG E, MAIN UPR & AMAREO & 4818 & 8045 & 13491 & 3226 \\
\hline 13326REAZ010 M5 & BRG F, MAIN UPR & ROSA & 4804 & 7022 & 8904 & 2218 \\
\hline 13327REA Z010 M5 & BRG G, MAIN UPR & VERMELHO & 876 & 1638 & 1360 & 762 \\
\hline 13328REA Z011 M5 & BRG H,MAIN UPR & BRANCO & 19 & 97 & 24 & 78 \\
\hline
\end{tabular}

\begin{tabular}{|c|c|c|c|c|c|c|}
\hline CÓDIGO & DESCR ÇÃO & COR & $\mathbf{E}_{\text {mín. }}$ & $\mathbf{E}_{\text {máx. }}$ & $\mathbf{P P}$ & $Q^{*}$ \\
\hline 13341REA Z010 M5 & BRG A, MAIN LWR & AZUL & 69 & 213 & 87 & 144 \\
\hline 13342REA Z010 M5 & BRG B, MAIN LWR & PRETO & 1430 & 2166 & 1882 & 736 \\
\hline 13343REAZ010 M5 & BRG C, MAIN LWR & MARROM & 4458 & 6184 & 6941 & 1726 \\
\hline 13344REA Z010 M5 & BRG D, MAIN LWR & VERDE & 5639 & 8455 & 12249 & 2816 \\
\hline 13345REAZ010 M5 & BRG E MAIN LWR & AMAREO & 4810 & 8036 & 13485 & 3227 \\
\hline 13346REA Z010 M5 & BRG, F MAIN LWR & ROSA & 4849 & 7065 & 8940 & 2216 \\
\hline 13347REAZ010 M5 & BRG, G MAIN LWR & VERMELHO & 881 & 1642 & 1364 & 762 \\
\hline 13348REA Z011 M5 & BRG H,MAIN LWR & BRANCO & 19 & 97 & 24 & 78 \\
\hline
\end{tabular}

Fonte: Autoria própria (2008).

\section{Considerações Finais}

O intuito central deste artigo foi avaliar que tipo de política de gestão de estoque de bronzinas estava sendo colocado em prática. Para isso, todos os amostrais de bronzinas foram estudados e a partir dos resultados obtidos, pode-se concluir que a proposta política de ressuprimento de bronzinas com base no cálculo de LEC, PP e ES (Lote Econômico de Compra, Ponto de Pedido e Estoque de Segurança) traz consideráveis reduções tanto nos volumes 
(quantidades) de itens a serem estocados, quanto nos valores do estoques "parados" e redução para zero de falta das mesmas. Além disso, observou-se que para importação das bronzinas do Japão e a Tailândia necessitam-se de Lead Times de reposição de 150 dias e de 180 dias, respectivamente.

As origens não podem apresentar ciclos de reposição menores que estes solicitados. Isso pode significar "perdas" ou "custos" desnecessários para fomentar o sistema logístico que atende a empresa Honda Automóveis tanto no Brasil Ltda., quanto em outros países onde o transporte, o acondicionamento, o número de funcionários e o nível de satisfação dos clientes podem ser significativamente "abalados". Isso principalmente por que a maior parte dos itens exigem reposição diária na produção. Neste trabalho o modelo de processo de reposição para a Honda Automóveis do Brasil, com a finalidade de aumentar seu nível de segurança, em busca de adequação e equilíbrio no estoque de Bronzinas mostrou-se satisfatório. Os resultados mais expressivos podem ser sintetizados em "ganhos" significativos ou "gastos desnecessários" com a atual política de gestão de estoques.

No caso dos estoques das Bronzinas do modelo FIT atingiu-se uma redução do estoque em torno de $\mathrm{R} \$ 800$ mil, uma redução de aproximadamente $42 \%$ que pode ser considerado como um valor que não foi gasto para a reposição plena dos estoques. Isso se levar em conta que seria necessário um maior espaço físico para o armazenamento de todos esses itens para a política anterior.

No caso do estoque de Bronzinas do modelo CIVIC a "economia" seria por volta de $\mathrm{R} \$ 170$ mil o que representaria uma redução de aproximadamente $33 \%$, dependendo do poder de compra que se deseja atingir, como função dos valores do fator " $k$ ".

Uma limitação verificada no estudo consiste no "volume" (quantidade) de estoque dos itens de baixa demanda que apresentavam muito altos desde a antiga gestão. Isso provoca um maior intervalo de tempo para que este estoque entre em equilíbrio. Além disso, cuidados devem ser tomados para as Bronzinas por efeitos de cálculo da relação demanda e estoque de segurança, as variações podem afetar significativamente os estoques, em que determinadas peças o tempo de reposição pode ser reduzido e para outras esse tempo pode ser ampliado.

\section{Agradecimentos}

Os autores agradecem todo o apoio dado pelos colaboradores e gestores da HAB, Honda Automóveis Brasil, Sumaré e pelas informações fornecidas quando solicitadas. Agradecimentos também são direcionados ao aporte financeiro provindo das Faculdades Network, Sumaré, SP. 


\begin{abstract}
The aim of this article was developed to attain an equilibrium in the crankshaft bearing (parts used in piston engines) inventory stock for CIVIC and FIT automobile models in the Honda Automobile Corporation. It was intend to improve the capability and to decrease the costs with inventory by using an adequate control of replacement. It was compared the actual inventory with those calculated stock parameters. It was found that the new inventory parameters have decreased the amount of studied items. In the case of the inventories of the crankshaft bearing of FIT and CIVIC automobiles models decreasing in a order of magnitude $\mathrm{R} \$ 800,000(42 \%)$ and $\mathrm{R} \$ 170,000(33 \%)$ were respectively attained when comparing with the current inventory replacement politic. It was also observed that attention must be taken when determining the inventory stock parameters. Variations in demand and the safety inventory values can significantly affect the lead time for replacement of the items.
\end{abstract}

Key-words: inventory stock control, safety stock, replacement.

\title{
Referências
}

BALLOU, R. H. Gerenciamento da cadeia de suprimentos: planejamento, organização e logística empresarial. 4. ed. São Paulo: Bookman, 2001.

BOWERSOX, D. J., CLOSS, D. J. Logística Empresarial: o processo de integração da cadeia de suprimento. São Paulo: Atlas, 2001.

CASTRO, J. G., PIZZOLATO, N. D., A programação de lotes econômicos de produção (ELSP) com tempos e custos de setup dependentes da seqüência: um estudo de caso, Revista Gestão Industrial, v. 01, n. 03: pp.70-80, 2005

cross ${ }^{\text {ref }}$

CHAN, C. K.; KINGSMAN, B. G.; WONG, H. The value of combining forecasts in inventory management: a case study in banking. European Journal of Operational Research, v. 117, p. 199-210, 1999.

cross ref

CORREA, H. L.; GIANESI, I. G. N; CAON, M. Planejamento, Programação e Controle da Produção. 4. ed. São Paulo, 2001

DIAS, M. A. P. Administração de materiais: resumo da teoria, questões de revisão, exercícios, estudos de caso. Edição Compacta. $4^{\mathrm{a}}$ ed. São Paulo: Atlas, 1997.

FERREIRA, Fernando. Negócios: $O$ que é importante na minha empresa? Disponível em: http://www.portalmix.com.br/diariodosulpub/ntfernando. Acesso em: 29 mar. 2008.

FRANCISCHINI, Paulino G.; GURGEL, Floriano do Amaral. Administração de materiais e do Patrimônio. São Paulo: Pioneira, 2002.

GAITHER, N.; FRAIZER, G. Administração da Produção e Operações. $8^{\circ}$ ed. São Paulo: Thomson, 2004.

GARCIA, L.C.; OSÓRIO, W.R. Determinação de Parâmetros de Estoque para Itens de Medicamento de Baixo Giro em Farmácias Hospitalares e Convencionais, Revista Administração (Faculdades Network), Brasil, v. II, Ano II, n. 1, p. 47-56, 2008.

GARCIA, L.C.; PEREIRA, M.; OSÓRIO, W.R. Parâmetros de estoque: estudo de caso de itens de medicamento em farmácias hospitalares e convencionais, Revista de Gestão Industrial, submetido ,2009.

cross ref

KLASSEN, R.; MENOR, L. The process management triangle: An empirical investigation of process trade-offs.

Journal of Operations Management, v.25, p. 1015-1034, 2007.

cross ${ }^{\text {ref }}$ 
KREVER, M.; WUNDERINK, S.; DEKKER, R.; SCHORR, B. Inventory control based on advanced probability theory, an application. European Journal of Operational Research, v. 162, p. 342-358, 2003.

crossef

LENARD, J. D.; ROY, B. Multi-item inventory control: A multicriteria view. European Journal of Operational Research, v. 87, p. 685-692, 1995.

cross ${ }^{\text {ref }}$

MARTINS, P.G., ALT, P.R.C. Administração de Materiais e Recursos Patrimoniais. São Paulo, Saraiva, 2003.

MOREIRA, D. A. Administração da Produção e Operações. 1. ed. São Paulo: Pioneira, 1993.

PARTOVI, F. Y.; ANANDARAJAN, M. Classifying inventory using an artificial neural network approach, Computers and Industrial Engineering, v. 41, p. 389-404, 2002.

cross'

PEREIRA, M., Logística Hospitalar: Reposição Contínua de Medicamentos, Moinho Editorial, ISBN: 856143700-6, $1^{\mathrm{a}}$. edição, p. $128,2008$.

RODRIGUES, D. M.; SELLITTO, M.A. práticas logísticas colaborativas: o caso de uma cadeia de suprimentos da indústria automobilística, Revista de Administração (R. Adm), São Paulo, v.43, n.1, p.97-111, jan./fev./mar. 2008

SANDRINI, L.G.; MESQUITA, M. A. O trade-off entre a folga na capacidade de produção e o nível de estoque, Revista Gestão Industrial, v. 04, n. 04: p. 217-233, 2008

cross ${ }^{\text {ref }}$

SANTOS, A.M., RODRIGUES, I. A. Controle de Estoque de Materiais com Diferentes Padrões de Demanda: Estudo de Caso em uma Indústria Química, Gestão \& Produção, v. 13, n.2, p.223-231, 2006.

crossef

SILVA, T. G., BARBOZA, F.; MARUJO, L. G., Análise dos impactos das diferentes políticas de gestão dos estoques de suprimentos em uma empresa do setor de bebidas através de simulação, Revista Gestão Industrial, v. 04, n. 04: p. 34-75, 2008

cross ${ }^{\text {ref }}$

TUBINO, D.F. Manual de Planejamento e Controle da Produção. São Paulo, Atlas, 2004.

TURBAN, E.; McLEAN, E.; WETHERBE, J. Tecnologia da informação para gestão. Porto Alegre: Bookman, 2004.

WANKE, P. Gestão de Estoques na Cadeia de Suprimentos: Decisões e Modelos Quantitativos. Rio de Janeiro:

Editora Atlas, 2003.

ZOMERDIJK, L. G.; VRIES, J. An organizational perspective on inventory control: Theory and a case study, International Journal of Production Economics, v. 81-82, p. 173-183, 2003.

cross'ref

\section{DADOS DOS AUTORES:}

\section{Fábio Jun Kunigami}

Honda Automóveis Brasil Ltda, HAB

Supervisor de Controladoria de Estoques

Endereço: Av. Ampélio Gazzetta, 2445, 13460-000, Nova Odessa, SP, Brazil

Telefones para contato: (55) 1935213319 ou 1991500988

e-mail: fabio_jun@hondabr.com.br 


\section{Wislei Riuper Osório}

Faculdades Network e UNICAMP, Universidade Estadual de Campinas

Administração e Engenharia de Materiais

Coordenador de Curso de Administração, Pesquisador Colaborador

Endereço: Av. Ampélio Gazzetta, 2445, 13460-000, Nova Odessa, SP, Brazil

Telefones para contato: (55) 1935213319 ou 1991500988

e-mail: wislei@,fem.unicamp.br

Recebido para publicação em: 10/09/2009

Aceito para publicação em: 03/12/2009 